\title{
Prognostic significance of primary tumour volume in nasopharyngeal carcinoma - a single institute study
}

\author{
Shamsundar S. ${ }^{1}$, Jagannath K.P. ${ }^{2 *}$, Niveditha S. ${ }^{3}$, Aradhana K. ${ }^{4}$, Nanda R. ${ }^{5}$, Thejaswini B. ${ }^{6}$ \\ DOI: https://doi.org/10.17511/ijmrr.2019.i01.05 \\ ${ }^{1}$ S.D. Shamsundar, Assistant Professor, Department of Radiation Oncology, Kidwai Memorial Institute of Oncology, Bangalore, Karnataka, \\ India. \\ 2* Jagannath K.P., Associate Professor, Department of Radiation Oncology, Kidwai Memorial Institute of Oncology, Bangalore, Karnataka, \\ India. \\ ${ }^{3}$ Niveditha S., Resident, Department of Radiation Oncology, Kidwai Memorial Institute of Oncology, Bangalore, Karnataka, India. \\ ${ }^{4}$ K. Aradhana, Associate Professor, Department of Radiation Oncology, Kidwai Memorial Institute of Oncology, Bangalore, Karnataka, India. \\ ${ }^{5}$ R. Nanda, Associate Professor, Department of Radiation Oncology, Kidwai Memorial Institute of Oncology, Bangalore, Karnataka, India. \\ ${ }^{6}$ B. Thejaswini, Professor, Department of Radiation Oncology, Kidwai Memorial Institute of Oncology, Bangalore, Karnataka, India.
}

Introduction: Nasopharyngeal carcinoma is very uncommon in the southern part of India, the ageadjusted incidence rate is less than 1 per 1,00,000 population. This study is undertaken to evaluate the outcome of nasopharyngeal carcinoma and its correlation with Primary tumor volume. Material and methods: Total of 50 non-metastatic nasopharyngeal carcinoma patients treated with concurrent chemo radiation between January 2013 and December 2015 were included in the study. All patients were treated via IMRT with dose of 66-70Gy, along with concurrent chemotherapy. Results: The median follow up for the group was 24 months. The median Gross tumor volume of primary disease and nodal disease was 61.6 cubic centimetres and 35.4 cubic centimeters respectively. The 2 year Disease free survival and Overall survival for the entire group was $64 \%$ and $68 \%$ respectively. There was significant difference $(p-0.018)$ between disease free survival of low volume disease group (LVD) which was $78 \%$ as compared to high volume disease (HVD) group 52\% at 24 months, similarly Overall survival was also significantly better ( $p-0.015)$ in LVD group as compared to HVD group $80 \%$ vs $55 \%$ at 24 months. Conclusion: Our patients had large volume primary disease, the OS and DFS was significantly better in LVD patients, adjuvant chemotherapy after concurrent chemoradiotherapy had no additional benefit for LVD patients but improved DFS and MFS in HVD Patients.

Keywords: Nasopharyngeal Carcinoma, Tumour volume, Prognostic factor

Corresponding Author

Jagannath K.P., Associate Professor, Department of Radiation Oncology, Kidwai Memorial Institute of Oncology, Bangalore, Karnataka, India.

Email: dr.jaganathkp@gmail.com

\section{How to Cite this Article}

Shamsundar SD, Jagannath $K P$, Niveditha $S$, Aradhana K, Nanda R, Thejaswini B. Prognostic significance of primary tumour volume in nasopharyngeal carcinoma - a single institute study. Int J Med Res Rev. 2019;7(1):24-29.

Available From

https://ijmrr.medresearch.in/index.php/ijmrr/article/ view/1031

$\begin{array}{cc}\begin{array}{c}\text { Manuscript Received } \\ 2018-11-02\end{array} & \begin{array}{c}\text { Review Round } \mathbf{1} \\ 2018-11-10\end{array} \\ \text { Conflict of Interest } & \text { Funding } \\ \text { No } & \text { Nil }\end{array}$

Review Round 2
2018-11-16
$\begin{gathered}\text { Ethical Approval } \\ \text { Yes }\end{gathered}$

Review Round 3

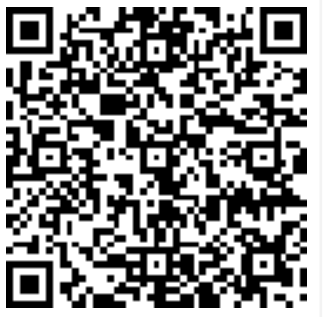

(C) 2019 by S.D. Shamsundar, Jagannath K.P., Niveditha S., K. Aradhana, R. Nanda, B. Thejaswini and Published by Siddharth Health Research and Social Welfare Society. This is an Open Access article licensed under a Creative Commons Attribution 4.0 International License https://creativecommons.org/licenses/by/4.0/ unported [CC BY 4.0]. 


\section{Introduction}

Nasopharyngeal carcinoma (NPC) is a very uncommon malignancy in most parts of India, the age-adjusted incidence rate in population-based registry Bangalore which is located in southern part of India is less than 1 per $1,00,000$ population, however the incidence is more in the north-eastern parts of India, rate ranging from 3 in Sikkim to 19.4 per $1,00,000$ in Kohima. These low rates are comparable to those commonly quoted for other Caucasoid populations of 0.5 to 2.0 per 100000 .

However higher incidence is seen in Chinese populations with an age adjusted rate of 30 per 100 000 for males and 13 per 100000 for females [1]. Tumor volume has been recognized as an important prognostic factor in the outcome of NPC, in addition to histopathologic type, tumor stage and intracranial extension $[2,3,4]$. However, the most common staging systems used for nasopharyngeal carcinoma that is the Ho's and AJCC staging do not take tumour volume or size of disease into consideration but take anatomical site involved and extension to surrounding structures to classify the T stage [5].

But numerous studies have shown a significant association of tumor volume and outcome in NPC, but most of these studies are done in oriental populations where the incidence of NPC is high. Radiotherapy (RT) has been the mainstay of treatment of NPC over many years as its anatomical location is not easily amenable to surgery and also NPC is a radiosensitive malignancy which responds well to RT. The results of chemo radiation have been good in early stage disease and mixed in locally advanced disease. Various studies have proven the efficacy of concurrent chemo radiotherapy (CCRT) over RT alone in the treatment of locally advanced [6]. We have taken up this study to assess the volume of disease and correlate the outcome with the tumor volume in our patients treated with chemo radiation who are mainly from Bangalore which is low incidence region and to compare the results with those of high incidence region.

\section{Material and Methods}

This study is a retrospective analytical study conducted in the department of Radiation oncology, Kidwai Memorial Institute of Oncology, Bangalore

Patient Selection: Inclusion Criteria \& Exclusion Criteria
Fifty primary nasopharyngeal carcinoma patients treated with concurrent chemo radiation with or without adjuvant chemotherapy between January 2013 and December 2015 in our institute were included in the study, all the patients belonged to the local ethnicity. The patients who did not complete the planned radiotherapy and patients who had previously received radiotherapy or chemotherapy were excluded from the analysis.

Patient Evaluation

All of the patients completed a pre-treatment evaluation, including a complete patient history, physical examination and haematology and biochemistry profiles. Magnetic resonance imaging (MRI) or computed tomography (CT) of the nasopharynx and neck was performed for the staging evaluations. Chest radiography, abdominal ultrasonography and a bone scan was done. All of the patients were staged according to the 7th edition of American Joint Committee on Cancer (AJCC) system

Tumor volume measurement- The gross tumor volume was manually outlined in the planning system based on the contrast enhanced simulation CT scan, if pre-treatment MRI images were available then these images were fused in treatment planning system for contouring by a radiation oncologist.

The Primary tumor volume (PTV) included the primary nasopharyngeal disease and retro pharyngeal nodes, the involved neck nodes were contoured separately as nodal volume (GTVn). The primary and node tumor volumes were calculated using the planning system (Eclipse planning system, version 7.3, Varian Medical Systems, (Palo Alto, USA)

Treatment Planning- All patients were treated on a Varian Clinac linear accelerator via IMRT technique to a dose of 66-70Gy, along with concurrent weekly Cisplatin $40 \mathrm{mg} / \mathrm{m2}$ or Carboplatin AUC 2. Few patients received Adjuvant Chemotherapy comprising of Cisplatin $100 \mathrm{mg} / \mathrm{m} 2$ along with 5 fluorouracil $1000 \mathrm{mg} / \mathrm{m} 2$. All patients were followed up with imaging.

Statistics- The Kaplan-Meier method was used for calculation of Overall survival and disease free survival, statistical significance was defined to be a probability value of 0.05 . The significance of potential prognostic factors was assessed by Cox proportional hazards model. IBM SPSS Statistics software was used for statistical analysis. 


\section{Results}

Patient and Treatment Characteristics (Table 1): All the 50 patients had received concurrent Chemoradiation, among them majority received cisplatin $44(88 \%)$ and only $6(12 \%)$ received carboplatin, however $23(46 \%)$ received adjuvant chemotherapy, and the rest 27 (54\%) did not.

Tumor volume and Stratification (Table 2): The median Gross tumor volume of primary disease was 61.6 cubic centimetres (cc) (range 14.9-191.6 cc), and that of node was 35.4 cubic centimetres (range 0-196.9). The patients were divided into two groups High volume disease (HVD) and Low volume disease (LVD) based on the median gross tumor volume of the primary (GTVp) disease.

Patients with GTVp of less than or equal to $61.6 \mathrm{cc}$ were categorized into LVD and those with GTVp of more than $61.6 \mathrm{cc}$ were categorized as HVD. The patient and treatment characteristics were similar in both the groups except node positivity which is comparatively higher in HVD group ( $P$ value0.065).

Treatment outcomes: The median follow up period was 24 months ranging from 12 to 66 months. The 2 year Disease free survival (DFS) and overall survival (OS) for the entire group was 64\% and $68 \%$ respectively. The OS and DFS of LVD group was $80 \%$ and $78 \%$ respectively at 24 months, which was significantly better than os of $55 \%$ and DFS of $52 \%$ in HVD group at 24 months (Figure I). Table 3 shows the pattern of recurrence in both the groups. The addition of Adjuvant chemotherapy had no effect on the DFS in LVD group (Figure II), but in HVD group it improved the both metastasis free survival and DFS (Figure III).

\section{Table-1: Patient and Treatment Characteristics.}

\begin{tabular}{|l|l|}
\hline \multicolumn{1}{|c|}{ Sample size } & \multicolumn{1}{c|}{50} \\
\hline Mean age & 42 years \\
\hline Sex Distribution & $38(76 \%)$ \\
\hline Male & $12(24 \%)$ \\
\hline Female & \multicolumn{2}{|l|}{} \\
\hline GTV DOSE & $38(76 \%)$ \\
\hline 70Gy & $12(24 \%)$ \\
\hline$<70 G y$ & $61.6 c c$ \\
\hline Median Volume & $35.05 c c$ \\
\hline GTV-p & \multicolumn{2}{|l}{} \\
\hline GTV-n &
\end{tabular}

\begin{tabular}{|l|l|}
\hline II & $3(6 \%)$ \\
III & $39(78 \%)$ \\
IVA & $5(10 \%)$ \\
IVB & $3(6 \%)$ \\
\hline Histology & $23(46 \%)$ \\
\hline Undifferentiated & $13(26 \%)$ \\
\hline Non-keratinizing SCC & $44(88 \%)$ \\
\hline Concurrent Chemotherapy & $6(12 \%)$ \\
\hline Cisplatin & \\
Carboplatin & $23(46 \%)$ \\
\hline Adjuvant Chemotherapy & $27(54 \%)$ \\
\hline Yes & \multicolumn{2}{|l|}{} \\
\hline No
\end{tabular}

Table-II: Distribution of characteristics in Low volume and High Volume Disease group.

\begin{tabular}{|c|c|c|}
\hline $\begin{array}{c}\text { Median Primary } \\
\text { tumor Volume (PTV) }\end{array}$ & $\begin{array}{c}\text { LOW VOLUME }(\mathrm{n}=24) \\
\text { PTV }<61.6 \mathrm{ccm}\end{array}$ & $\begin{array}{c}\text { HIGH VOLUME }(\mathrm{n}=26) \\
\text { PTV }>61.6 \mathrm{ccm}\end{array}$ \\
\hline MEAN AGE & $42.17 y r s$ & $41.84 y \mathrm{rs}$ \\
\hline \multicolumn{3}{|l|}{ SEX } \\
\hline Male & $18(75 \%)$ & $20(76.9 \%)$ \\
\hline Female & $6(25 \%)$ & $6(23.1 \%)$ \\
\hline \multicolumn{3}{|c|}{ CONCURRENT Chemotherapy } \\
\hline Cisplatin & $21(87.5 \%)$ & $23(88.5 \%)$ \\
\hline Carboplatin & $3(12.5 \%)$ & $3(11.5 \%)$ \\
\hline \multicolumn{3}{|l|}{ ADJUVANT CT } \\
\hline Yes & $12(50 \%)$ & $11(42.3 \%)$ \\
\hline No & $12(50 \%)$ & $15(57.7 \%)$ \\
\hline \multicolumn{3}{|c|}{ NODAL STATUS(p-value 0.068) } \\
\hline $\mathrm{N}$ negative & $13(54.2 \%)$ & $5(19.2 \%)$ \\
\hline N positive & $11(45.8 \%)$ & $21(80.8 \%)$ \\
\hline
\end{tabular}

Table-III: Pattern of recurrence in both groups of Patients.

\begin{tabular}{|l|l|l|}
\hline \multicolumn{1}{|c|}{ Recurrence } & \multicolumn{1}{|c|}{$\begin{array}{c}\text { Low Volume disease } \\
\text { group }\end{array}$} & \multicolumn{1}{c|}{$\begin{array}{c}\text { High Volume disease } \\
\text { group }\end{array}$} \\
\hline $\begin{array}{l}\text { No } \\
\text { Recurrence/mets }\end{array}$ & $19(79 \%)$ & $13(50 \%)$ \\
\hline Local Recurrence & $3(12.5 \%)$ & $6(23.1 \%)$ \\
\hline Metastatic & $2(8.5 \%)$ & $7(26.9 \%)$ \\
\hline
\end{tabular}
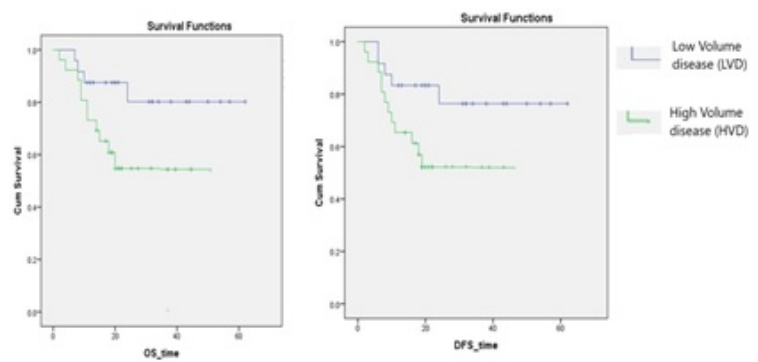

Figure-I: Overall survival (OS) and Disease free survival (DFS) in Low volume and High Volume disease group. 


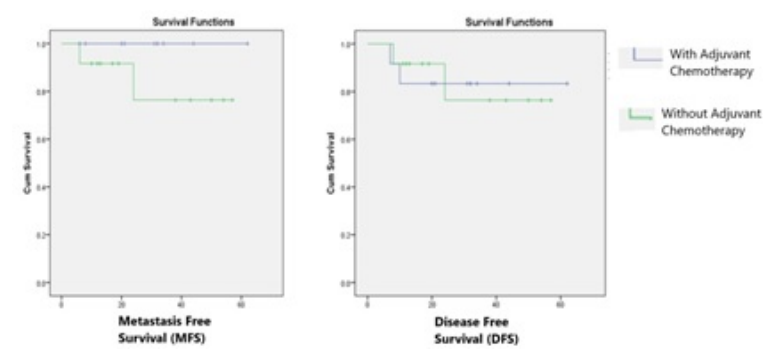

Figure II: The Metastasis free (MFS) and Disease free survival in Low volume disease group.
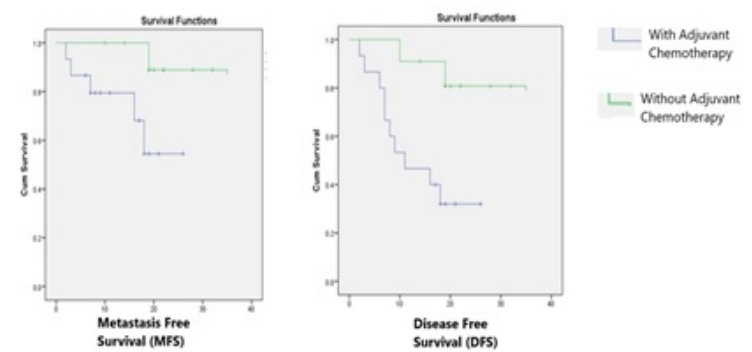

Figure III: The Metastasis free (MFS) and Disease free survival in High volume disease group.

\section{Discussion}

Numerous studies have shown primary tumor volume to be a significant factor of treatment outcome. Study by Chua et al [7] observed PTV to be an independent prognostic factor much better than the traditional Ho's $\mathrm{T}$ classification as a predictor of local control. Chen et al [10] found that tumour volume was better at predicting cumulative survival for patients with NPC than the widely used AJCC staging system. This was confirmed by Multivariate analysis after adjusting for $\mathrm{T}$ stage, $\mathrm{N}$ stage and disease stage. But most of these studies are done in populations where NPC is endemic, where as our study is done in a population where NPC is uncommon.

The median volume of primary disease in our study was $61.6 \mathrm{ccm}$ with range from 14.9 to $191.6 \mathrm{ccm}$, which is large as compared studies by wu et al [7] and chu et al [8], where the median primary tumor volume was $20.35 \mathrm{ml}$ (range, $0.44-192.63 \mathrm{ml}$ ) and $12.94 \mathrm{~mL}$ (range, $1.25-69 \mathrm{~mL}$ ) respectively.

In our study the OS and DFS are significantly better in LVD group compared to HVD group, which is similar to studies published by chu et al [7] and willner et al who showed that PTV more than $60 \mathrm{ccm}$ and $64 \mathrm{ccm}$ had poor outcome [8].
However, studies from china and Taiwan showed PTV above $15 \mathrm{ml}$ showed significantly poor outcome $[5,6]$ but in these studies the median PTV was ranging from 13 to $20 \mathrm{ccm}$, which is much smaller compared to the previous studies and our study. Similarly study by Sze et al [11] suggested that patients with primary tumor along with retropharyngeal node volumes of over $15 \mathrm{ccm}$ had inferior local control and that the local control rate decreased by $1 \%$ as the primary tumor volume increased by $1 \mathrm{ccm}$.

However in the study by kim et al [5] the primary tumor volume had significant correlation to local control and nodal volume was significantly associated with nodal control. Large nodal volume greater than $5 \mathrm{ccm}$ had significantly lower survival rate. Where as in study by Chua et al [7] nodal volume greater than $4 \mathrm{ccm}$ was associated with more distant failure rate with no correlation to disease specific survival.

In our study also the metastatic rate was much higher in the HVD arm but was not statistically significant probably due to the small number of patients in the study by wu et al [5], patients with PTV more than $33.75 \mathrm{ccm}$ had significantly more metastasis, however other studies have mainly compared PTV with survival outcomes rather than metastasis free survival $[9,10]$.

The role of concurrent chemoradiotherapy followed by adjuvant chemotherapy was established in the Intergroup study, for NPC patients with AJCC stage II-IVB [12], similarly Cheng et al [13] reported that stage II-III NPC would benefit from CCRT followed by adjuvant chemotherapy. The improvement in survival rate with adjuvant chemotherapy was not observed in low-risk patients without parapharyngeal invasion or skull base involvement.

In our study also $50 \%$ of LVD and $43 \%$ of HVD patients received adjuvant chemo-therapy, there was no difference in LVD group in terms of DFS or metastasis free survival (MFS), but in HVD group patients receiving adjuvant chemotherapy had significantly better DFS and MFS (figure 3 ). These results are similar to study by chu et al, where addition of adjuvant chemotherapy improved the 3year metastasis-free survival from $68.3 \%$ to $100 \%$ and the 3-year recurrence-free survival increased from $69.6 \%$ to $94.1 \%$. The benefit of adjuvant chemotherapy was not observed in the small tumor volume group [6]. 


\section{Conclusion}

The patients treated in our center had large volume primary disease compared to similar patients in endemic areas, the OS and DFS was significantly better in LVD patients, adjuvant chemotherapy after concurrent chemoradiotherapy had no additional benefit for LVD patients but improved DFS and MFS in HVD Patients.

\section{What this study adds to existing knowledge}

To the best of our knowledge this is the first study from our country which has looked at tumor volume and treatment outcomes in Nasopharyngeal tumors.

There is extensive literature on this topic mainly from countries such as china, Taiwan and Korea where the incidence is high, but limited studies are present from places of low incidence such as other Asian countries. Our study from low incidence area shows how the disease behaves differently in terms of having large disease volumes, and its correlation with treatment outcome.

\section{Contribution of Authors}

S D Shamsundar: Formulated the idea for study, collection of data, manuscript writing and editing. Jaganath K P: Collection of data, editing manuscript. Niveditha S: Formulated the idea for study, collection of data. $\mathbf{K}$ Aradhana: collection of data, statistical analysis. R Nanda: Collection of data, manuscript writing and editing. B Thejaswini: Formulated the idea for study.

\section{Reference}

01. Amal Chandra Kataki, Malcolm J Simons, Ashok Kumar Das, Kalpana Sharma, and Narinder Kumar Mehra. Nasopharyngeal carcinoma in the North eastern states of India. Chin J Cancer. $2011 \mathrm{Feb} ; 30(2) 106-113$.

[Crossref]

02. Geara FB, Sanguineti G, Tucker SL, et al. Carcinoma of the nasopharynx treated by radiotherapy alone- determinants of distant metastasis and survival. Radiother Oncol. 1997 Apr;43(1)53-61.

[Crossref]
03. Hsu MM, Huang SC, Lynn TC, Hsieh T, et al. The survival of patients with nasopharyngeal carcinoma. Otolaryngol Head Neck Surg. 1982 May-Jun;90(3 Pt 1)289-95.

[Crossref]

04. Shanmugaratnam K, Chan SH, de-Thé G, et al. Histopathology of nasopharyngeal carcinomacorrelations with epidemiology, survival rates and other biological characteristics. Cancer. 1979 Sep; 44(3)1029-44.

[Crossref]

05. Jeong-Hyun Kim and Joon-Kyoo Lee. Prognostic Value of Tumor Volume in Nasopharyngeal Carcinoma. Yonsei Medical Journal. $2005 ; 46 ; 2 ; 221-7$.

[Crossref]

06. Lin JC, Jan JS, Hsu CY, et al. Phase III study of concurrent chemoradiotherapy versus radiotherapy alone for advanced nasopharyngeal carcinoma- positive effect on overall and progression-free survival. J Clin Oncol. 2003;Feb 15;21(4)631-7.

DOI: $10.1200 /$ JCO.2003.06.158 [Crossref]

07. Zheng Wu, Mo-Fa Gu, Rui-Fang Zeng, Yong Su and Shao-Min Huang. Correlation between nasopharyngeal carcinoma tumor volume and the 2002 International Union Against Cancer tumor classification system. Radiation Oncology. 2013;8;87.

[Crossref]

08. Chu et al. Primary Tumor Volume of Nasopharyngeal Carcinom- Significance for Recurrence and Survival. J Chin Med Assoc. 2008;71(9)461-466.

[Crossref]

09. Chua DT, Sham JS, Kwong DL, et al. Volumetric analysis of tumor extent in nasopharyngeal carcinoma and correlation with treatment outcome. Int J Radiat Oncol Biol Phys. 1997 Oct $1 ; 39(3) 711-9$.

[Crossref]

10. Willner J, Baier $K$, Pfreundner L, et al. Tumor volume and local control in primary radiotherapy of nasopharyngeal carcinoma. Acta Oncol. $1999 ; 38(8) 1025-30$.

[Crossref] 
11. Sze WM, Lee AW, Yau TK, et al. Primary tumor volume of nasopharyngeal carcinomaprognostic significance for local control. Int J Radiat Oncol Biol Phys. 2004; May 1;59(1)21-7. DOI: $\quad 10.1016 /$ j.ijrobp.2003.10.027 [Crossref]

12. Chen C, Fei Z, Pan J, Bai P, Chen L. Significance of primary tumor volume and T-stage on prognosis in nasopharyngeal carcinoma treated with intensity-modulated radiation therapy. Jpn J Clin Oncol. 2011;41;537-542.

[Crossref]
13. Al-Sarraf M, LeBlanc M, Giri PG, et al. Chemoradiotherapy versus radiotherapy in patients with advanced nasopharyngeal cancer- phase III randomized Intergroup study 0099. J Clin Oncol. 1998 Apr;16(4)1310-7.

DOI: $\quad 10.1200 / J C O .1998 .16 .4 .1310 \quad$ [Crossref]

14. Cheng SH, Tsai SY, Yen KL. Prognostic significance of parapharyngeal space venous plexus and marrow involvement- potential landmarks of dissemination for stage I-III nasopharyngeal carcinoma. Int J Radiat Oncol Biol Phys. 2005 Feb 1;61(2)456-65.

[Crossref] 